\title{
RELAÇÕES SOCIAIS: COMBATE E CRÍTICA A TODAS AS FORMAS DE DESIGUALDADES
}

\author{
SOCIAL RELATIONS: COMBAT AND CRITICISM FOR ALL FORMS OF \\ INEQUALITIES
}

Wagner dos Reis Marques Araújo ${ }^{1}$, Antonio Marcos de Oliveira Siqueira ${ }^{2}$, Aldair Oliveira de Andrade ${ }^{3}$ e Roberta Ferreira Coelho de Andrade ${ }^{4}$

1 Universidade do Estado de Minas Gerais, UEMG-Abaeté/MG, Brasil, marquesreis@hotmail.com, ORCID: https://orcid.org/0000-0003-0793-0043

2 Universidade Federal de Viçosa, Viçosa/MG, Brasil, antonio.siqueira@ufv.br, ORCID: https://orcid.org/0000-0001-9334-0394

3 Programa de Pós-Graduação em Ciências e Humanidades (PPGCH), Universidade Federal do Amazonas, Humaitá/AM, Brasil, aldairandrade@yahoo.com.br, ORCID: https://orcid.org/0000-0001$\underline{5205-9766}$

4 Departamento de Serviço Social, Universidade Federal do Amazonas, Manaus/AM, Brasil, roberta ufam@yahoo.com.br, ORCID: https://orcid.org/0000-0002-6535-0760

\section{ARTICLE INFO}

Article history:

Received 2020-12-20

Accepted 2020-12-20

Available online 2020-12-20
Palavras-chave: Gênero. Sexualidade. Transexualidade. Relações de poder. Ensino. Desigualdades.

Keywords: Sexuality. Transsexuality. Power relations. Teaching. Inequalities.

Neste seu terceiro número, do volume 3 (2020), o Comitê Editorial da Revista Relações Sociais prossegue dando visibilidade às temáticas anteriormente pouco contempladas (ANDRADE et al., 2020) e, sobremaneira, prestando-se a dar voz a jovens pesquisadores/as, confirmando o propósito maior deste periódico: o combate e a crítica a todas as formas de desigualdades.

Vive-se um momento incertezas e negacionismo da ciência, percebamos vários movimentos de resistência frente a perda de espaços democráticos conquistados nas últimas décadas. Assiste-se ao enfraquecimento de políticas públicas de inclusão social, de incentivo à pesquisa e inovação tecnológica com cortes de bolsas de pesquisas, dentre outras ações de predação governamental. Por isto mesmo (e muito mais), afirmamos que as estruturas sociais da sociedade capitalista patriarcal produzem opressões de classe, gênero e raças, subalternizando sujeitos a modos de ser.

Tais opressões têm adquirido nuances ainda não vistas neste país, uma vez que o governo atua como agente (re) produtor de todos os "ismos" que intersectam com a pobreza extrema que avança no Brasil. Isto é, a violência estrutural se instala no país como uma 
política de governo corroborada, sobretudo, pela pandemia Covid-19. De todo modo, esta edição da REVES assume o propósito com autores (as) que, em sua maioria, nos apimentaram com resultados de estudos que tem a ver com as suas identidades de resistência e "lugar de fala". Assim, seguramente, nos colocamos como "espaço de fala" para dar voz e visibilidade à pesquisas que abordam temáticas sobre gênero, sexualidade, transexualidade, relações de poder, entre outras. Já que nos referimos ao "lugar de fala", um conceito tão utilizado nos últimos tempos, porém mal interpretado, cabe pontuar que "o lugar social não determina uma consciência discursiva sobre esse lugar. Porém, o lugar que ocupamos socialmente nos faz ter experiências distintas e outras perspectivas" (RIBEIRO, 2019, p. 69).

Com isto queremos afirmar, com base no que indica Djamila Ribeiro, que a REVES tem a pretensão de promover uma "multiplicidade de vozes", de modo a quebrar o discurso autorizado, classista e hegemônico dos espaços de divulgação cientifica, que se "pretende universal". Tudo isso tem a ver com as estruturas de dominação, "a classe que é a força material dominante da sociedade é, ao mesmo tempo, sua força espiritual dominante" (MARX e ENGELS, 2007, p. 47). As ideias da classe dominante são, segundo Marx e Engels (2007), "as ideias dominantes" de cada época, ou seja, os modos de pensar de uma elite privilegiada que controla a produção, circulação e o acesso ao conhecimento, portanto, partir dessa concepção, instituiu-se este periódico como um espaço de fala contrahegemônico.

Seguimos, assim, em edições futuras com a proposta de contribuir com debates que promovam reflexões as transformações sociais urgentes para uma maior equidade de classe e gênero e raças/etnia.

Abre este número o artigo "Sistema de cotas e fraudes em uma universidade federal brasileira", de Sales Augusto dos Santos e Matheus Silva Freitas, que apresenta os resultados de uma pesquisa acerca do ingresso de estudantes subcotistas étnico-raciais em cursos de "alto prestígio" na Universidade Federal de Viçosa, cujos dados apontam o ingresso fraudulento de estudantes brancos/as nas subcotas étnico-raciais destinadas a estudantes pretos/as, pardos/as e indígenas, bem como indicam a pouca presença de estudantes mulheres pretas nos cursos de alto prestigio, segundo os autores, em razão de fraudes praticadas por estudantes brancos/as. A pesquisa concluiu que o ingresso coletivo dos/as estudantes pretos/as nos "cursos de alto prestígio dessa universidade não foi significativo, isto é, quantitativamente crescente, ao contrário do que se esperava".

Rodrigo Lemos Simões, em "Legislação e ações visando à diversidade étnico-racial no ensino superior: estudo comparativo dos PDIS de IES públicas e comunitárias gaúchas" apresenta os resultados de um estudo sobre diversidade-racial na legislação educacional 
brasileira, onde analisa acerca das ações afirmativas desenvolvidas no âmbito das Instituições de Ensino Superior (IES) públicas e comunitárias gaúchas. O autor buscou verificar a forma como as IES trabalham na perspectiva das ações voltadas às questões étnico-raciais, constatando que, de forma geral, os documentos analisados são pouco utilizados nas IES o autor presume que essa legislação é, muitas vezes, desconhecida pela comunidade acadêmica.

Em "Significados do direito ao voto por parte de presos provisórios e adolescentes internados", Eder Aparecido de Carvalho, Alexandre da Silva de Paula e Sergio Kodato apresentam os resultados de uma pesquisa que buscou compreender os conceitos e representações que circulam no imaginário social, sobre o pleno direito do cidadão maior de 16 e o menor de 21 anos privado de liberdade de exercer sua cidadania plena. Discutiu-se, com base na pesquisa bibliografia e empírica a relação entre o direito ao voto, formação da cidadania e reinserção social de encarcerados, constando que os argumentos utilizados para negar o direito ao voto a esses sujeitos, partem do paradigma da retirada de direitos como punição, por outro lado, os argumentos a favor desse direito alicerçam-se numa imagem destes como cidadãos portadores de direitos.

No artigo "Feminismo e discurso de gênero em redes sociais: empoderamento feminino?", Maria Cecilia Baini e Adail Sobral trazem os resultados de um estudo cuja análise parte de discussões estabelecidas nas redes sociais sobre questões de gênero em torno do lançamento do filme Mulher-Maravilha, na página de Facebook oficial da obra. Foram analisados discursos mediados por computador, com base em quatro categorias discursivas, a saber: estrutura, sentido, interação e comportamento social. O estudo aponta que os discursos de empoderamento feminino passam, inevitavelmente, por critérios preestabelecidos e impõe uma imagem idealizada de mulher.

Hercules Guimarães Honorato, em "O curso de direito internacional dos conflitos armados e a utilização da educação a distância: a visão dos seus discentes" apresenta as contribuições da utilização das ferramentas da plataforma Moodle no Curso de Direito Internacional dos Conflitos Armados (CDICA). A pesquisa aponta, com base na pesquisa qualitativa, contribuições, a saber: fórum de discussão aberto, aplicação e ampliação dos estudos; criação de uma pasta virtual; possibilidade de especialização futura para os egressos do curso, dentre outras relacionadas à interatividade na plataforma.

No artigo "Educação de Jovens e Adultos e homoafetividade: relato das concepções dos alunos e debate acerca do tema", Tito Marcos Domingues dos Santos problematiza a importância da ação pedagógica acerca da homoafetividade no contexto da educação, apontando "o espaço de sala de aula enquanto lócus favorável à reflexão e ao combate a toda expressão de preconceito". A pesquisa indica que a discussão da temática contribuiu para concepções favoráveis à diversidade de gênero, bem como a intervenção pedagógica 
mostrou que "concepções negativas acerca da homoafetividade eram resultantes da falta de informação, estudo e diálogo acerca do tema".

Jaime Peixoto, no artigo "Resistir para re(existir): reflexões sobre a produção de resistências por estudantes gays na Escola de Ensino Médio", traz os resultados de uma pesquisa de mestrado em educação, que investigou os modos inventivos que jovens gays produzem resistências e enfrentamentos às práticas homofóbicas no espaço escolar, partindo da perspectiva pós-crítica, o autor u sobre a evidenciação dos processos de criação de estratégias de resistências, discute as estratégias de "resistências que tais sujeitos engendram dentro das relações de forças envolvendo a vivência transgressora do gênero e da sexualidade no meio escolar em tempos de conservadorismos".

Em "Perspectiva socioambiental no discurso jornalístico do site da agência Amazônia Real, Ingrid Gomes Bassi analisa o conceito discursivo socioambiental de um site de notícias, apontando como resultado da pesquisa que o site de notícias desenvolveu "o discurso jornalístico à luz da alteridade", bem como problematiza as matérias jornalísticas com base em "interpretações discursivas críticas as complexidades do contextos socioambiental amazônico", porém, "a partir do olhar narrativo desses atores costumeiramente subalternizados pela grande imprensa.

No artigo "Da Universidade ao mundo do trabalho: prática docente na formação de futuros gestores", Corina Alves Farinha e Patrícia Rosânia de Sá Moura apresentam os resultados de um estudo que visou identificar o quanto os conteúdos das disciplinas de Políticas Públicas, Direitos Humanos e Gestão de Pessoas são capazes de sensibilizar os estudantes sobre as atitudes discriminatórias e/ou preconceituosas com pessoas LGBT no ambiente organizacional. A pesquisa aponta, como dado conclusivo, que conteúdos e componentes curriculares são "instrumentos importantes para ampliar ou modificar a percepção dos estudantes quanto" à orientação LGBT.

"A feminine of no one's own in Charlotte Tábua Rasa", Eider Madeiros, Letícia Simões Velloso Schuler, Mariana Pinheiro Ramalho e Hermano de França Rodrigues discutem acerca da "própria ruptura que o corpo trans feminino evoca". Os/as autores tomam como base as contribuições de Bento (2008), Jorge e Travassos (2018), para discutir como o "corpo de uma mulher trans em um cenário ficcional da política brasileira seria capaz de traçar as difíceis fronteiras dos discursos, posses e domínios da linguagem", mediante "deslocamentos e esforços às reinscrições e às fissuras" de transgressão do feminino.

Em "A Igbtifobia presente no interior de uma Escola pública em São Gonçalo - RJ", Renan Corrêa dos Santos, Denize Sepulveda, José Antonio Sepulveda e Daniel Carvalho de Almeida Lima nos contemplam com os resultados de uma pesquisa realizada em uma instituição de ensino público municipal do estado do Rio de Janeiro. A pesquisa objetivou 
saber se no espaço da escola ocorrem práticas conservadoras, preconceituosas e discriminatórias contra alunxs LGBTIS+, e como se desenvolvem e se os valores religiosos de professorxs e funcionárixs interferem nelas. A pesquisa aponta, com dado relevante, que os/as alunxs LGBTIS+ sofrem práticas discriminatórias no ambiente escolar, bem como atitudes lesbofóbicas por parte de um funcionárixs em relação a trocas de afetos de um casal de lésbicas, em detrimento de um casal heterossexual.

Os autores Leonardo Mozdzenski e Albert de Albuquerque, no artigo "LGBT rights are human rights: social work and the fight against the Igbtphobic discourse of gay cure"' analisam comentários de assistentes sociais em relação ao conteúdo do vídeo Para o Serviço Social, não existe "cura gay", uma campanha criada pelo Conselho Federal de Assistência Social (CFESS). Como um achado relevante, a pesquisa aponta que os enunciados se mostraram favoráveis à proposição das terapias de (re)orientação sexual. De forma conclusiva, os achados da pesquisa são organizados "em cinco categorias analíticas: a retórica cis-hetero-compulsória, a retórica da "liberdade de pensamento", a retórica do "direito de escolher", a retórica neoconservadora e a retórica religiosa".

No artigo "Uma análise criminológico-crítica sobre os discursos discentes acerca da criminalização da homofobia", Túlio Vinícius Andrade Souza e Maria Cristina Lopes de Almeida Amazonas apresentam os resultados de um estudo que buscou entender os discursos produzidos pelos futuros operadores do Direito no que se refere à criminalização da homofobia. A pesquisa partiu da abordagem acerca do conhecimento do Projeto de Lei 122/2016 (“criminalização da homofobia") e, sobremaneira, dos posicionamentos que os sujeitos emitiram sobre a proposta legislativa e a sua correlação com a vertente teóricoepistemológica da Criminologia Crítica e a teoria queer.

Em "O senso comum em livros didáticos de sociologia", Ricardo Cortez Lopes analisa a noção de senso comum nos livros didáticos de sociologia brasileira, cujos resultados da pesquisa apontam que a definição indireta se baseia no zeitgeist hegeliano, que "concebe o senso comum como um bloco monolítico de pensamento filosófico que se opõe dualmente à ciência". O autor aponta, de forma conclusiva, a relação entre a retirada e a reinserção do ensino de filosofia e sociologia nos currículos escolares brasileiras e o conceito "senso comum".

“Espanha, habitação e COVID-19”, artigo de Tiago Augusto da Cunha analisa as medidas adotas pelo governo espanhol, visando à proteção social da população mais vulnerável durante o ápice da crise sanitária. O autor traz uma interessante reflexão a partir de sua análise da experiência espanhola acerca das estratégias de enfrentamento da pandemia, com vista a "contribuir para o enriquecimento do corolário de estratégias visando à provisão e à segurança habitacional, advogando pela perenidade de algumas delas". 
No artigo "Folia de Reis em Minas Gerais como ritual religioso, Festa Popular e Patrimônio Imaterial", André Luis Santos de Souza e André Luiz Ribeiro de Araújo analisa elementos simbólicos ligados a Folia de Reis de Carlos Chagas (MG), especialmente presentes nas performances dos foliões durante o ritual. A pesquisa apresenta, como um dado conclusivo, que a "Folia de Reis, além de uma festa religiosa, um patrimônio imaterial, também é um tipo de ritual ligado à cosmologia do sistema religioso católico praticado na região mineira estudada há mais de um século".

"Discriminação étnica em Moçambique: elo-base que exige eliminação para paz efectiva" traz uma pesquisa que problematiza acerca da discriminação étnica em Moçambique que, segundo o autor, tem uma gênese histórica e foi enraizando-se na sociedade ao longo dos tempos, tornando-se a causa-base da acumulação de ódios. $O$ autor aponta que "a discriminação étnica promove a deturpação da história nacional, desalinha as políticas públicas e inviabiliza" a efetivação de uma Unidade Nacional e, sobretudo, influencia nos processos de busca da Paz.

Por fim, "A importância dos jogos cooperativos no ambiente escolar", de Paulo Roberto Barbosa dos Santo e Alexsandro Santos da Silva, analisa o processo participativo dos alunos do Ensino Fundamental II, da Escola Municipal Alda Nunes Santos, buscando introduzir e demonstrar a importância dos jogos cooperativos no contexto escolar.

\section{Referências}

ANDRADE, R. F. C. de; ANDRADE, A. O. de .; SIQUEIRA, A. M. de O. .; ARAÚJO, W. dos R. M. . DEBATES NECESSÁRIOS: AMBIENTE, EDUCAÇÃO E DIVERSIDADES. REVES Revista Relações Sociais, [S. I.], v. 3, n. 1, p. 000i-00iv, 2020. DOI: 10.18540/revesvl3iss1pp000i-00iv. Disponível em: https://periodicos.ufv.br/reves/article/view/9975 . Acesso em: 19 dez. 2020. MARX, Karl; ENGELS, Friedrich. A ideologia alemã. São Paulo: Boitempo, 2007. RIBEIRO, Djamila. Lugar de fala. Sueli Carneiro: São Paulo; Polén, 2019. (Coleção Feminismos Plurais). 